\title{
Housing Market Bubbles and Currency Crisis: The Case of Thailand
}

\author{
Kar-yiu Wong \\ University of Washington
}

March 2001

(forthcoming in Japanese Economic Review) 


\begin{abstract}
This paper explains with a simple model the collapse of the housing market in Thailand prior to the economic crisis in 1997. It is shown that successive periods of impressive growth of the economy has created not only higher demands for housing, but also an increase in people's optimism about the conditions of the market in the future. Both oversupply and bubbles were formed before the market finally crashed. The model is used to explain some of these phenomena, and to describe the nature of the bubbles. An ironic possibility is that a faster and more persistent growth of the economy tends to increase the vulnerability of the firms in the market.
\end{abstract}

This paper was presented at the international conference on "The Asian Crisis: The Economics Front," which was held in Seattle, December 29-30, 1998. Thanks are due to Chong K. Yip for valuable comments and to Yi-Chi Chen for his able and efficient assistance.

(c) Kar-yiu Wong. 


\section{Introduction}

The recent Asian financial/currency crisis, which began with the floating of the Thai baht on July 2, 1997, has surprised many people. Not only the depth of the impacts on these economies, but also the speed of the contagion and the number of countries affected were unexpected and unprecedented. What seemed to be more puzzling was that these economies had been doing fine before the crisis, with impressive growth and solid fundamentals. Even before the eve of the crisis, nearly all forecasts were predicting positive and high growth rates for these economies for the years of 1997 and 1998. How wrong they were!

What has happened and what went wrong? Economists, trying to catch up, are searching for answers.

This paper focuses on Thailand and suggests a theory. There are several reasons for looking at Thailand. ${ }^{1}$ First, nearly all countries in East and Southeast Asia experienced pressure in the crisis, but Thailand was the first country to experience tremendous currency speculative attacks and the first one to be forced to significantly devalue its currency. Second, the current financial crisis seems to be different from many previous ones in many ways. ${ }^{2}$ In particular, these countries have shown high growth rates before the crisis, ${ }^{3}$ and the governments had responsible fiscal and macroeconomic policies. Third, Thailand did show some warning signs of a troubled economy before the crisis although most people had chosen to ignore them. Probably the most troubling spot in the economy was its housing and real estate sector.

The troubles in the Thai housing market can be partially attributed to the growth of the economy, which took off sometime in the sixties to sev-

\footnotetext{
${ }^{1}$ See Wong (2000) for an analysis of the crisis in South Korea.

${ }^{2}$ Krugman (1998) and Corsetti, et. al. (1998) have suggested that the first-generation crisis models, which focus on the inconsistency between a fixed exchange rate regime and the fiscal and macroeconomic policies pursued by the governments, and the secondgeneration models, which emphasize multiple equilibria, expectation of the speculators, and self-fulfilling are not sufficient to explain the current Asian crisis. See also a recent survey by Saxena and Wong (2000).

${ }^{3}$ South Korea is one of the four Asian newly industrialized countries, while countries like Thailand, Malaysia, Indonesia, and the Philippines are emerging economies.
} 
enties, and continued to grow with high rates but little interruptions. ${ }^{4}$ The long period of growth has created an over-heated housing market. New housing units were built to satisfy the ever-growing demands caused by the hot economy. The supply of housing was further fueled in the nineties by the liberalization of capital inflow as a result of the passage of Bangkok International Banking Facilities in 1992, which provided opportunities to domestic financial institutions for borrowing foreign loans at low rates and then lending the money to local housing developers. ${ }^{5}$

The sector began to feel pressure in 1995. The pressure came from two fronts: the overproduction of houses and office space, and the central bank's squeeze on lending. The overproduction of housing created excess supply, while developers were reluctance to lower the housing prices to clear the market. ${ }^{6}$ The lending squeeze worsened the cash flow problems of the developers, making them more difficult to get the finance to survive. By 1996, the sector showed many signs of troubles. The sector's debts totalled around 800 billion bahts in 1996. In February 1997, several months before the crisis, Somprasong Land Plc defaulted on interest payments on euro-convertible debentures worth $\$ 80$ million.

The Somprasong default was followed by those of other firms, which then put pressure on many banks and financial institutions, especially the small ones. In June, one month before the floating of the baht, 16 finance companies were suspended. Two months later, another 42 received the same fate. Toward the end of the year, 56 more were closed permanently. ${ }^{7}$

The growth of the Thai economy has unintentionally enhanced the impact of the problems in the housing market on the rest of the economy, as different sectors became interrelated and interdependent. As the housing market were having difficulties, the banking and financial sector became squeezed. This in turn put pressure on other parts of the economy. When the conditions of the economy got worse, investors lost confidence and started to move their capital out of the country. The latter effect accentuated like a snow ball

\footnotetext{
${ }^{4}$ See Lo and Wong (1998) for statistical data of Thailand and some other countries in this crisis.

${ }^{5}$ Loans from financial institutions to property developers in Thailand totalled 523 billion baht in 1995, up from 436 in 1994 and 264 billion baht in 1993. By the end of June, 1996, the loans reached 768 billion baht (Parnssonthorn, 1996).

${ }^{6}$ There might be little rooms for the developers to lower the housing prices because of high costs of production.

${ }^{7}$ See Terdudomtham (1997).
} 
and very soon, with the participation of currency speculators, capital flight became unmanageable. This bank-run type capital outflow became so huge that eventually the central bank of Thailand could no longer defend the baht. ${ }^{8}$

Observing the troubles in the Thai housing market is straightforward, but explaining them is much more difficult. This paper attempts to do that with a simple model, which is based on the following assumptions and features of the sector and the economy. First, growth of the economy has created rising demand on housing, which then led to rising housing prices and production. Second, because construction of housing takes some time, developers face uncertainty about the conditions of the market in the future at the time they choose to start the housing projects. Third, nearly uninterrupted periods of growth with high rates have made developers overoptimistic. Fourth, the liberalization of the capital market as a result of the Bangkok International Banking Facilities in 1992 at a time when the sector was overheated and when foreign loans were available at low interest rates had led to a sharp rise in external debts. Fifth, the pegging of the baht over a long period of time has given people the false sense of security so that most of the external loans raised were denominated in foreign currencies such as the yen and the dollar, and that little, if any, hedging against exchange risks has been done. The devaluation of the baht has led to huge capital loss of the financial institutions, but shortly before the actual devaluation, there had been an expectation by many people of one in the near future, prompting many people to convert their domestic financial assets to foreign currency. The latter action led to further drainage of the stocks of foreign reserves held by the central bank, thus deepening the crisis. Sixth, the financial squeeze on lending by the central bank in 1995 has worsen the cash flow problems of the developers at a time when they had difficulty in selling all the properties developed. Seventh, the collapse of the housing market, marked by company failure and bankruptcy, created bad loans and hardship to the financial system, making the repayment of external debts difficult. ${ }^{9}$

We characterize the overoptimism in housing properties as bubbles. A more explicit explanation of the concept of bubbles used in this paper will be given later. Also given later is an explanation of why bubbles were formed.

\footnotetext{
${ }^{8}$ For more information about the housing market in Thailand, see, for example, Renand, et. al. (1998) and Wong (1998).

${ }^{9}$ For a model that explains the crisis in South Korea using herding behavior, see Wong (2000).
} 
Other than the existence of uncertainties in the market and economy, we use a concept called herd behavior, which describes the tendency of people's actions to follow those taken by some others so that they tend to act as a herd. Herding can take the extreme form that people make decisions simply based on the observed actions of others, rather than on their own private information.

Herding is not a new concept in the economics literature. Keynes' beauty contest is a famous example ${ }^{10}$ but this concept has also been applied to other areas such as investment. ${ }^{11}$ Our model is similar in many ways to that used by Scharfstein and Stein (1990). One basic feature of the present model is that there are so many uncertainties that investors do not make their investment decisions based solely on the private information they possess. Instead, investors find it better to follow the investment decisions of other people. What is important is that it could be rational for people to herd, instead of being guided by the private information they possess. ${ }^{12}$

In this paper, we construct a simple model to show the relationship between economic growth, herding, excess supply, growth and collapse of the housing market, and a financial crisis. Our model is built on the features of a housing market described above, and is used to illustrate how previous successes of the economy and the market could lead to overproduction of housing, thus increasing the riskiness and vulnerability of the investment projects. We argue that the longer the period of growth the market experiences, the more vulnerable future projects may become.

This paper is organized as follows. In Section 2, we introduce the main features of the model. We focus on the case before the economy takes off, a steady state in which the conditions of the economy remain stationary over time. In Section 3, we consider a shock to the housing market caused by an unexpected growth of the economy. This raises the demand for housing in certain states of nature, but at the same time makes the future demand uncertain. We explain how firms choose their output, assuming that some firms are optimistic about the future but some firms are pessimistic. In Section 4, we explain what losses firms may expect to get in bad times. In Section 5, we investigate how firms may become more optimistic if the good

\footnotetext{
${ }^{10}$ It is said that in a beauty contest, judges usually give scores based on the scores they guess other judges are going to give instead of on how well they think about the participants.

${ }^{11}$ See Devenow and Welch (1996), and Saxena and Wong (2000) for two recent surveys.

${ }^{12}$ See, for example, Calvo and Mendoza (1998), and Devenow and Welch (1996).
} 
state happens. We explain why herd behavior can lead to overoptimism about the market conditions in the future. In Section 6, we explain how bubbles may be formed, and how overoptimism may increase the vulnerability of many firms and the market. Section 7 extends the model to one with multiple periods or one in which the conditions of a good state get improved over time. The last section concludes.

\section{The Model: The Pre-growth Situation}

Consider a competitive housing market in an economy. ${ }^{13}$ For simplicity, assume that housing is a homogeneous product, and that the market is small in the economy so that the rest of the economy can be taken as given. The economy is connected to the world financial markets so that domestic firms and individuals have access to foreign loans. Housing, however, is a nontradable good.

The economy initially is in a stationary state, but then it starts to take off, causing a possible rise in the demand for housing. In this section, we introduce the major features of the present model, with a focus on the initial stationary state. The time subindex is suppressed in this section. Denote the demand for housing by the following function,

$$
p=h^{b}(D)
$$

where $p$ is the market price, and $D$ is the quantity demanded. [Ignore the superscript " $b$ " for the time being.] It is assumed that $h^{b \prime}(D)<0$, where a prime denotes a derivative. The demand function is illustrated in Figure 1 by the downward sloping schedule labeled $h^{b}$. This demand function is publicly known.

There are $2 n$ competitive firms supplying housing, where $n$ is a large number and is fixed in the present analysis. All firms have identical technology and are facing the same set of input and output prices. Each firm employs labor (and possibly other inputs) to produce housing according to

\footnotetext{
${ }^{13}$ The Thai construction sector is relatively quite competitive, with a large number of small companies. For example, there were nearly 10,400 construction firms in the country by the end of 1994, and most of them are small, Thai-owned enterprises, with only a few joint ventures with foreign interests. (The Economist Intelligence Unit Country Profile, 1997-98: 39)
} 
the following function:

$$
q^{i}=f\left(\ell^{i}\right),
$$

where $q^{i}$ is the output of firm $i, \ell^{i}$ is the labor input, and the production function $f\left(\ell^{i}\right)$ is twice differentiable, and strictly increasing and concave; i.e., $f^{\prime}>0$ and $f^{\prime \prime}<0 .{ }^{14}$

Denote the prevailing wage rate by $w$, which for simplicity is assumed to be fixed in the present analysis. In addition, there is a fixed cost, $F$ (possibly due to other inputs not considered explicitly in the present paper), which is the same for every firm. However, the production process takes one period to complete. While the firms receive revenue after selling the output in the housing market, they have to hire the workers and pay the variable and fixed costs, $w \ell^{i}+F$, one period in advance. Such non-synchronization of payments and receipts means a cash flow problem for each firm. It is assumed that to cover the costs the firm borrows money in any period from an international capital market at an exogenously given interest rate $r$. In the next period, the total repayment of the loan is equal to $\left(w \ell^{i}+F\right)(1+r)$. The future value of the profit of the firm is given by

$$
\pi^{i}=p q^{i}-\left(w \ell^{i}+F\right)(1+r) .
$$

The firm is supposed to choose, at the time the housing project is to start, the optimal amount of labor to maximize its (future value of) profit, taking the prices as constant. The first-order condition, using condition (2) and assuming an interior solution, is

$$
p f^{\prime}\left(\ell^{i}\right)=w(1+r),
$$

which can be rearranged to give the demand for labor:

$$
\ell^{i}=g(p ; w, r) .
$$

Note that with identical technologies, all firms make the same production decision. Because the production function is strictly concave in labor input, the second-order condition is satisfied:

$$
\frac{\partial^{2} \pi^{i}}{\partial\left(\ell^{i}\right)^{2}}=p f^{\prime \prime}<0 .
$$

\footnotetext{
${ }^{14}$ For simplicity, we assume that labor is the only variable input. All other inputs are assumed to be fixed and are ignored in the production function.
} 
It is easy to show that the labor demand is increasing in $p$ but decreasing in $w$ and $r .{ }^{15}$ The optimal output is then given by the following supply function:

$$
q^{i}=\phi^{i}(p ; w, r) \equiv f(g(p ; w, r)),
$$

which is also increasing in $p$ but decreasing in $w$ and $r$. The aggregate supply function is therefore

$$
Q_{1}=2 n q^{i}=2 n \phi^{i}(p ; w, r) .
$$

The output function given in (7) can be substituted into equation (3) to express the profit as a function of the price, when taking $w$ and $r$ as parameters:

$$
\pi^{i}=\theta^{i}(p ; w, r)
$$

Function $\theta^{i}(p ; w, r)$ is increasing and convex in $p$, but decreasing in $w$ and $r .^{16}$

When given input prices, the market supply function in (8) is illustrated in Figure 1 by the upward sloping schedule EG plus portion of the vertical axis OR. ${ }^{17}$ We assume that the minimum point of the average cost schedule of a representative firm (not shown in the figure) corresponds to price level $p_{0}$, which is the height of point $\mathrm{E}$. This means that to have output from the firms, the market price has to be at least $p_{0} \cdot{ }^{18}$ This critical price level can be obtained from the profit function given by (9):

$$
\theta^{i}\left(p_{0} ; w, r\right)=0
$$

For $p \geq p_{0}$, the envelope theorem implies that

$$
\frac{\partial \pi^{i}}{\partial p}=q^{i}>0
$$

\footnotetext{
${ }^{15}$ Totally differentiate (4) to give

$$
p f^{\prime \prime}\left(\ell^{i}\right) \mathrm{d} \ell^{i}+f^{\prime}\left(\ell^{i}\right) \mathrm{d} p=(1+r) \mathrm{d} w+w \mathrm{~d} r .
$$

Rearranging the terms will give the result.

${ }^{16}$ The profit function is used in fields like international trade, where it is called the revenue function, GNP function, or GDP function. For the properties of a GDP function, see, for example, Wong (1995).

${ }^{17}$ Since the labor demand depends positively on the market price of output, so does the output.

${ }^{18}$ We assume that firms do not produce if the expected profit is negative.
} 
The dependence of the firm's profit on the price is illustrated graphically in Figure 2. Schedule ABC, which is called the profit curve of a representative firm, shows the dependence of the firm's maximum profit (when positive) on the market price. This schedule has the following properties: It is increasing and convex, and cuts the horizontal axis at a positive price, $p_{0}$. In other words, the profit of the firm is positive if the market price is greater than $p_{0}$ and is zero, with no output, if $p \leq p_{0}$.

The market equilibrium is illustrated in Figure 1. It is represented by the point of intersection, E, between the demand curve $h^{b}$ and the aggregate supply schedule OREG. Mathematically, the equilibrium condition is given by

$$
Q=Q\left(h^{b}(Q) ; w, r\right)
$$

which is used to solve for the equilibrium output, $Q_{0}$. The equilibrium can then be used to solve for the equilibrium price, $p_{0}$. In the case shown, the firms earn zero profit at the equilibrium. In such a stationary economy, the equilibrium of the housing market remains unchanged over time, until some shocks arise.

\section{The Take-Off}

Consider a period labeled period 0 . Up to the beginning of this period, the market has been stationary, with the equilibrium represented by point $\mathrm{E}$ in Figure 1. There are $2 n$ firms, each of which earns zero profit.

Just before the firms choose the optimal labor input for producing housing in period 0 , it is known to everyone that the economy has taken off (but not known before this period); i.e., it is growing. ${ }^{19}$ This shock, which will affect the equilibrium of the housing market, is described by the following assumptions:

(i) Growth of the economy is expected to lead to an increase in the demand for housing.

(ii) There are two possible states of nature in period 1: "good" state and "bad" state. The probability of having the good state in period 1 is $\rho$ while that of having the bad state is $(1-\rho), \rho \in(0,1)$. If the good

\footnotetext{
${ }^{19}$ In other words, the shock is a surprising one so that no firm will change its output before period 0 .
} 
state occurs, the demand function for housing is given by $p_{1}^{g}=h^{g}\left(D_{1}\right)$ while that in the bad state is $p_{1}^{b}=h^{b}\left(D_{1}\right)$, with $h^{g}\left(D_{1}\right)>h^{b}\left(D_{1}\right)$ for all $D_{1}>0$, where $D_{1}$ is the aggregate production chosen by the firms. Both demands depend negatively on the price. For convenience, we further assume that the demand in the bad state is the same as that in the initial stationary state. ${ }^{20}$

(iii) The growth of the economy and the demand functions in the two states are public information, but the value of $\rho$ is unknown to the public.

The assumption that $\rho$ is unknown to everyone can be justified by the fact that growth of an emerging economy usually involves many new uncertainties. During the early stages of a take-off, people have little experience and knowledge about the nature of the growth. In particular, because probability is not observable and because there are not too many past observations, it is difficult to have a reliable (with a small standard deviation) estimate of the probability of any state.

In period 0 , all firms receive a signal, and based on that signal they estimate the value of $\rho$. For simplicity, we assume that there are two groups of firms, $n$ of them in each group, which can be labeled type- $\alpha$ and type$\beta$ firms (or $\alpha$-firms and $\beta$-firms), respectively. An $\alpha$-firm believes that the probability of the good state in period 1 is $\rho_{1}^{\alpha} \in(0,1)$ while a $\beta$-firm thinks that the good-state probability is $\rho_{1}^{\beta} \in[0,1)$, where $\rho_{1}^{\alpha}>\rho_{1}^{\beta}$. [The $\alpha$-firms are therefore optimists and the $\beta$-firms are pessimists in terms of what they think of the chance of the good state in the next period.] There can be many reasons why the firms have different beliefs of the good-state probability; for example, they may have received different signals, or they have managers of different characters. ${ }^{21}$ As a result, even though all firms have the same technologies, having different beliefs of the good-state probability implies that they generally will choose different production plans. ${ }^{22}$

\footnotetext{
${ }^{20}$ This assumption, which is made for simplicity, explains the superscript " $b$ " in function $h^{b}(D)$ introduced in the previous section.

${ }^{21}$ For example, Scharfstein and Stein (1990) distinguish between "good" and "bad" signals, and between "smart" and "dumb" managers. However, it is beyond the scope of this paper to model the herd behavior, and so we do not explain explicitly how $\rho_{1}^{\alpha}$ and $\rho_{1}^{\beta}$ are chosen.

${ }^{22}$ It will be more general if we assume a continuum of firms that are ranked by the degree of optimism about the good-state probability. In the present model, assuming only two types of firms is sufficient to bring out the main features of the present model.
} 
Both $\rho_{1}^{\alpha}$ and $\rho_{1}^{\beta}$ are public information, even though they are determined privately. The question one may ask is whether herding may exist in this period. It may, but this does not mean that $\rho_{1}^{\alpha}$ is necessarily equal to $\rho_{1}^{\beta}$, at least not in this period. First, it is not likely that full herding exists in the first period. Second, there are equal number of firms in each group. They are symmetric, and there is no good reason to predict whether $\alpha$-firms will revise $\rho^{\alpha}$ close to $\rho^{\beta}$ or the other way around. Third, herding effects are usually more powerful when one can observe the actions of others. This means that herding effect could be more powerful in later periods when differences in optimism lead to different actions and rewards.

Based on the predicted price levels in the two states and the firms' subjective beliefs of the good-state probability, the expected price level in period 1 of the $i$-firms are

$$
\widetilde{p}_{1}^{i} \equiv \rho_{1}^{i} p_{1}^{g}\left(D_{1}\right)+\left(1-\rho_{1}^{i}\right) p_{1}^{b}\left(D_{1}\right)
$$

where $i=\alpha, \beta$.

Assuming risk neutrality, each firm in period 0 has to choose the optimal labor employment to maximize its expected future value of profit, which is equal to

$$
\widetilde{\pi}_{1}^{i}=\widetilde{p}_{1}^{i} q_{1}^{i}-\left(w \ell_{0}^{i}+F\right)(1+r) .
$$

A comparison of equations (3) and (14) shows that, assuming a non-negative expected profit, the new demand for labor by firm $i$ in period 0 is equal to

$$
\ell_{0}^{i}=g\left(\widetilde{p}_{1}^{i} ; w, r\right),
$$

which gives the output level in the next period,

$$
q_{1}^{i}=\phi^{i}\left(\widetilde{p}_{1}^{i} ; w, r\right) \equiv f\left(g\left(\widetilde{p}_{1}^{i} ; w, r\right)\right) .
$$

Because of the positive relationship between probability and the expected price, when given the price level in each state, an increase in optimism will induce the firm to produce a higher production level, i.e., $q_{1}^{\alpha}>q_{1}^{\beta}$.

Because $\rho_{1}^{\alpha}>\rho_{1}^{\beta} \geq 0$, all $\alpha$-firms will have positive outputs. ${ }^{23}$ The $\beta$ firms, however, may or may not have positive outputs. In terms of the output chosen by the $\beta$-firms, three cases can be distinguished:

\footnotetext{
${ }^{23}$ To see this point, suppose that the bad state occurs. Since the market is shown to be big enough to support all the firms, it is certainly big enough for the optimistic $\alpha$-firms. In the good state, the demand is higher, meaing that the market is big enough to support at least all $\alpha$-firms.
} 
(a) All $\beta$-firms are producing a positive output.

(b) Some $\beta$-firms are producing a positive output but some $\beta$-firms are producing nothing.

(c) All $\beta$-firms are producing nothing.

These three cases are analyzed separately below. Note that we use $Q_{1}$ to represent the aggregate output in period 1 in general, but use $Q_{1}^{j}$ to represent the equilibrium output in case $(j), j=a, b, c$, which will be discussed below.

\subsection{Case (a)}

In this case, the aggregate supply of housing is

$$
Q_{1}=n\left(q_{1}^{\alpha}+q_{1}^{\beta}\right)=n\left[\phi^{\alpha}\left(\widetilde{p}_{1}^{\alpha} ; w, r\right)+\phi^{\beta}\left(\widetilde{p}_{1}^{\beta} ; w, r\right)\right] .
$$

The equilibrium of the housing market is described by

$$
Q_{1}=D_{1}
$$

The two equations in (13), two equations in (16), equation (17), and equation (18) are used to solve for $\widetilde{p}_{1}^{\alpha}, \widetilde{p}_{1}^{\beta}, q_{1}^{\alpha}, q_{1}^{\beta}, Q_{1}$, and $D_{1}$.

This equilibrium can be solved in a simple way. Using the equations of the expected price functions, (13), and the equilibrium condition (18), the output of each firm can be written as

$$
q_{1}^{i}=\sigma^{i}\left(Q_{1} ; \rho_{1}^{i}, w, r\right) \equiv f\left[g\left(\rho_{1}^{i} p_{1}^{g}\left(Q_{1}\right)+\left(1-\rho_{1}^{i}\right) p_{1}^{b}\left(Q_{1}\right) ; w, r\right)\right] .
$$

It is easy to show that function $\sigma^{i}$ is decreasing in $Q_{1} \cdot{ }^{24}$ The equilibrium can be determined by solving the following equation, which is obtained from (17):

$$
Q_{1}=n\left[\sigma^{\alpha}\left(Q_{1} ; \rho_{1}^{\alpha}, w, r\right)+\sigma^{\beta}\left(Q_{1} ; \rho_{1}^{\beta}, w, r\right)\right] .
$$

\footnotetext{
${ }^{24}$ Differentiation of $q_{1}^{i}$ with respect to $Q_{1}$ gives

$$
\frac{\partial \sigma^{i}}{\partial Q_{1}}=f^{\prime} g^{\prime}\left[\rho_{1}^{i} h^{g \prime}+\left(1-\rho_{1}^{i}\right) h^{b \prime}\right]<0 .
$$
}


In Figure $3, n \sigma^{\alpha}\left(Q_{1} ; \rho_{1}^{\alpha}, w, r\right)$ as a function of $Q_{1}$ is shown by schedule AB. The values of function $n \sigma^{\beta}\left(Q_{1} ; \rho_{1}^{\beta}, w, r\right)$ are added vertically to $\mathrm{AB}$, giving schedule CD. The equilibrium output is depicted by the intersection point between schedule CD and a $45^{\circ}$-line from the origin, shown as point E. Let this output be $Q_{1}^{a}$. Once the aggregate output is known, all other variables can be derived in a simple way. In particular, the market price and the profit of each firm in each state can be derived. In order for the $\beta$-firms to be willing to produce in this case, the resulting expected profit of each of them is non-negative. Another schedule, $\mathrm{A}^{*} \mathrm{~B}^{*}$, is also shown in Figure 3. It represents function $2 n \sigma^{\alpha}\left(Q_{1} ; \rho_{1}^{\alpha}, w, r\right)$ and is constructed so that its vertical height is twice that of schedule AB. Obviously, schedule CD lies between schedules $\mathrm{AB}$ and $\mathrm{A}^{*} \mathrm{~B}^{*}$.

The market equilibrium can also be shown in Figure 4. Given the demand in the two states, the expected demand perceived by $\alpha$-firms $(\beta$-firms) is illustrated by schedule $\tilde{h}^{\alpha}\left(\tilde{h}^{\beta}\right)$. Because $\alpha$-firms are more optimistic than $\beta$-firms, schedule $\tilde{h}^{\alpha}$ is higher than schedule $\tilde{h}^{\beta}$. Schedule HJ (plus segment OR of the vertical axis) represents the supply of all $\alpha$-firms or all $\beta$-firms. Since the two types of firms have the same number and same technologies, HJ horizontally bisects the space between the vertical axis and schedule EG. With an output of $Q_{1}^{a}$ of the sector, the equilibrium price in the good (bad) state in period 1 is equal to $p_{1}^{g}\left(p_{1}^{b}\right)$. This means that the expected price perceived by $\alpha$-firms ( $\beta$-firms) is equal to $\tilde{p}_{1}^{\alpha}\left(\tilde{p}_{1}^{\beta}\right)$, and they choose to produce an output of $Q_{1}^{\alpha}\left(Q_{1}^{\beta}\right)$, where $Q_{1}^{\alpha}+Q_{1}^{\beta}=Q_{1}^{a}$.

\subsection{Case (b)}

We now turn to case (b) in which some of the $\beta$-firms choose not to produce. Denote the number of $\beta$-firms with a positive output in equilibrium by $m$, where $0<m<n$. This case is similar to case (a), except that all the $\beta$-firms with a positive output have zero expected profit. Denote the expected price perceived by $\beta$-firms by $\widetilde{p}_{1}^{\beta}$. In other words,

$$
\widetilde{\pi}_{1}^{\beta}=\widetilde{p}_{1}^{\beta} f\left[g\left(\widetilde{p}_{1}^{\beta}\right)\right]-\left[w g\left(\widetilde{p}_{1}^{\beta}\right)+F\right](1+r)=0 .
$$

Since there are some $\beta$-firms that choose not to produce, the expected price $\widetilde{p}_{1}^{\beta}$ must be equal to $p_{0}$. The aggregate supply is defined as

$$
Q_{1}=n q_{1}^{\alpha}+m q_{1}^{\beta}=n \sigma^{\alpha}\left(Q_{1} ; \rho_{1}^{\alpha}, w, r\right)+m \sigma^{\beta}\left(Q_{1} ; \rho_{1}^{\beta}, w, r\right) .
$$


Two equations in (13), two equations in (16), equation (18), and equation (22) are used to solve for $\widetilde{p}_{1}^{\alpha}, q_{1}^{\alpha}, q_{1}^{\beta}, m, Q_{1}$, and $D_{1}$.

This equilibrium can be solved in a simple, recursive way. First, the expected price $\widetilde{p}_{1}^{\beta}\left(=p_{0}\right)$ is used to give $q_{1}^{\beta}$ by $(16)$, and to yield $D_{1}$ and $Q_{1}$ by (13) and (18). Denote the equilibrium quantity by $Q_{1}^{b}$. Once $D_{1}$ is known, equation (13) gives $\widetilde{p}_{1}^{\alpha}$, which is then used to calculate $q_{1}^{\alpha}$. Equation (22) gives the number of $\beta$-firms that have positive outputs.

\subsection{Case (c)}

We now turn to case (c), in which none of the $\beta$-firms has any incentive to produce anything. The simplest approach to analyzing this case is to derive the critical value of these firms' expectation of the good-state probability, $\rho_{1}^{c}$, which is the maximum perceived good-state probability with which all $\beta$-firms have no incentive to produce anything.

With no production by the $\beta$-firms, the aggregate supply is given by

$$
Q_{1}=n q_{1}^{\alpha}=n \sigma^{\alpha}\left(Q_{1} ; \rho_{1}^{\alpha}, w, r\right)
$$

Equation (23) can be solved for the equilibrium output, which is denoted by $Q_{1}^{c}$. Graphically, it can be solved by using Figure 3. Schedule AB represents $n \sigma^{\alpha}\left(Q_{1} ; \rho_{1}^{\alpha}, w, r\right)$, and the equilibrium output is then depicted by the point of intersection, F, between schedule $\mathrm{AB}$ and the $45^{\circ}$-line. This output, $\alpha$-firms' perceived good-state probability, $\rho_{1}^{\alpha}$, and condition (13) can be used to solve for the firms' expected price level in period 1 .

For $\beta$-firms, we want to determine the maximum good-state probability $\rho_{1}^{c}$ with which they choose to produce nothing. With this perceived probability, each $\beta$-firm earns zero profit, i.e.,

$$
\tilde{\pi}_{1}^{\beta}=\theta^{\beta}\left(\widetilde{p}_{1}^{\beta} ; w, r\right)=0,
$$

which can be solved for the corresponding expected price, $\widetilde{p}_{1}^{\beta}$. The critical good-state probability can then be solved from

$$
\widetilde{p}_{1}^{\beta} \equiv \rho_{1}^{c} p_{1}^{g}\left(Q_{1}^{c}\right)+\left(1-\rho_{1}^{c}\right) p_{1}^{b}\left(Q_{1}^{c}\right)
$$

The equilibrium in this case can be illustrated in Figure 5. Schedule $\tilde{h}^{\alpha}$ shows the expected demand perceived by the $\alpha$-firms, while HJ is the supply schedule of the $\alpha$-firms. The market output is given by the intersection 
between these two schedules, and is denoted by $Q_{1}^{c}$. This output leads to a market price of $p_{1}^{g}\left(p_{1}^{b}\right)$ if the good (bad) state occurs in period 1 . The expected price perceived by the $\alpha$-firms is equal to $\tilde{p}_{1}^{\alpha}$. Following the above analysis, we want to determine the maximum good-state probability perceived by the $\beta$-firms so that all of them choose to produce nothing. Recall that if the expected price is less than $p_{0}, \beta$-firms will produce no output in the long run. Thus making use of the price levels in the two states and $p_{0}$, we can determine the corresponding good-state probability, $\rho_{1}^{c}$, from which we can construct the expected demand curve perceived by the $\beta$-firms, $\tilde{h}^{\beta}$.

Proposition $10 \leq \rho_{1}^{c}<\rho_{1}^{\alpha}$.

Proof. If $\rho_{1}^{c}<0$, at least some $\beta$-firms will have a positive output. Suppose that $\rho_{1}^{c} \geq \rho_{1}^{\alpha}$. By its definition, the $\beta$-firms will be induced to produce something, and condition (24) will be violated. This is a contradiction.

Proposition 2 In cases (a) to (c), $q_{1}^{\alpha}>q_{1}^{\beta}$.

Proof. This proposition follows from the result that the $\alpha$-firms have a higher expected price than the $\beta$-firms have, and that the output is an increasing function of the expected price.

\section{The Losses}

We now turn to period 1 . In the beginning of this period, housing production by all optimistic firms and possibly some or all pessimistic firms is completed. The state of nature is revealed and the demand is known, depending on which state occurs. The equilibrium in the housing market is then achieved. After receiving revenue from the sale of housing, the firms repay the loan.

What state occurs has important consequences. We analyze the effects of each of the two states separately. In this section, we assume that the bad state occurs in period 1 and examine the consequences.

Proposition 3 (a) Whether in period 0 the $\beta$-firms have chosen to produce, $p_{1}^{b} \leq p_{0}$. (b) If $\rho^{\beta}>0$, then $p_{1}^{b}<p_{0}$.

Proof. (a) Suppose that $p_{1}^{b}>p_{0}$. Since the demand in a good state is higher than in a bad state, $p_{1}^{g}>p_{1}^{b}$, meaning that the expected price faced by all 
firms is greater than $p_{0}$, and that all firms will have an output greater than in period 0, i.e., $Q_{1}>Q_{0}$. However, an increase in output implies a decrease in the price level in the bad state, or $p_{1}^{b}<p_{0}$, contradicting the earlier assumption. (b) Suppose that $\rho^{\beta}>0$. We want to argue that $p_{1}^{b}=p_{0}$ can be ruled out. To see why, suppose $p_{1}^{b}=p_{0}$. This implies that all $\beta$-firms will have an expected price greater than $p_{0}$ and will produce an output greater than in period 0 , implying again that $Q_{1}>Q_{0}$ and $p_{1}^{b}<p_{0}$, contradicting to the assumption of $p_{1}^{b}=p_{0}$.

This proposition states that the price level in the bad state is lower than the price level before growth. ${ }^{25}$ It has important implications on the profits of the firms in the bad state, as the following proposition shows.

Proposition 4 Suppose that the bad state occurs in period 1. (a) All $\alpha$-firms earn a negative profit. (b) The profit of a $\beta$-firm is non-positive and its loss, if there is any, is less than that of an $\alpha$-firm. (c) The profit of a $\beta$-firm is zero if it is not producing or if its perceived good-state probability is zero and $p_{1}^{b}=p_{0}$.

Proof. (a) The profit of an $i$-firm in the bad state is given by

$$
\pi_{1}^{i b}=p_{1}^{b} q_{1}^{i}-\left(w \ell_{0}^{i}+F\right)(1+r),
$$

where $i=\alpha, \beta$. By Proposition 2 and because a firm earns zero profit before growth, the bad-state profit of any $\alpha$-firm as given by (26) is negative. In other words, an $\alpha$-firm can expect to receive a negative profit in the bad state, even though the expected profit, which the firm maximizes in period 0 , may be positive.

(b) For the same reason, the profit of a $\beta$-firm is non-positive when the bad state occurs. Since an $\alpha$-firm has a production higher than that of a $\beta$-firm (Proposition 2), and since profit is strictly concave in labor input, the loss of an $\alpha$-firm in the bad state must be greater than that of a $\beta$-firm.

(c) The bad-state profit of a $\beta$-firm is obviously zero if it is not producing anything in period 0 . Alternatively, suppose that its good-state probability is zero and that $p_{1}^{b}=p_{0}$. In this case, the $\beta$-firms are fully prepared for the bad state. Its expected price in period 0 is $p_{1}^{b}=p_{0}$. So if it does produce in

\footnotetext{
${ }^{25}$ Even if $\rho_{1}^{\beta}=0$, the period-1 price level can still be lower than that before growth.
} 
period 0 , its expected profit is zero. If the bad state does occur in period 1 , its realized profit is zero. ${ }^{26}$

By this proposition, if the bad state occurs, $\beta$-firms are glad to have been pessimistic.

The profit of an $\alpha$-firm can be illustrated by the profit curve $\mathrm{ABC}$ in Figure 2. In period 0 at the time when the production decision is made, the firm expects to make a profit equal to point $\mathrm{B}$, as the expected price in the next period is equal to $\widetilde{p}_{1}^{\alpha}$. Line $\mathrm{KBI}$ is tangent to the profit curve at point B. By equation (11), the slope of KBI is equal to the output chosen, $q_{1}^{\alpha}$. In period 1 , the state is revealed, and the price is $p_{1}^{g}$ if the good state occurs, or $p_{1}^{b}$ if the bad state occurs.

The profit curve shows the profit of an $\alpha$-firm at different prices under the condition that the output (and labor) is chosen optimally. The output that the firm can supply to the market, $q_{1}^{\alpha}$, was chosen in period 0 at a time when the actual price in period 1 is not known. Because the realized price is not the same as the expected price in any state (unless the good-state probability is equal to either 1 or 0 ), the realized profit is different from what the profit curve suggests. To be more explicit, the realized profit is given by the following equation,

$$
\pi_{1}^{\alpha}=p_{1} q_{1}^{\alpha}-\left(w \ell_{0}^{\alpha}+F\right)(1+r),
$$

where $q_{1}^{\alpha}$ and $\ell_{0}^{\alpha}$ are predetermined parameters in period 1. Equation (27) is illustrated by line KBI. If the market price is $p_{1}^{g}\left(p_{1}^{b}\right)$, the profit is depicted by point K (I). As Proposition 3 shows, the profit of an optimistic firm is negative if the bad state occurs.

What would happen if a firm receives a loss? The following options may be available to the firm: (i) to draw on previous profits to cover the loss; (ii) to raise further loans in the capital market; and (iii) to declare bankruptcy. Bankruptcy generates externality to the rest of the economy, and could be costly to a firm. ${ }^{27}$ If the loss is not of significant amount, and if it is of short-run nature, the firm may be able to afford it, which may be covered with previous savings or new loans.

\footnotetext{
${ }^{26}$ Of course, if the good state occurs, its realized profit is positive. In this case, all $\beta$ firms know that their initial belief of the value of the good-state probability is completely wrong.

${ }^{27}$ It is beyond the scope of this paper to model the cost of bankruptcy explicitly.
} 


\section{The Herding Effects}

We now examine the consequence if the good state occurs in period 1 , and then try to go beyond period 1. For the time being, we assume that the demand conditions in period 2 remain exactly the same as those in the previous period: The demand for housing in the good and bad states are given by $p_{2}=h^{g}\left(D_{2}\right)$ and $p_{2}=h^{b}\left(D_{2}\right)$, respectively, where $D_{2}$ is the quantity. The cost structures and the good-state probability also remain unchanged. All these pieces of information are known to everyone, except again that as before, the good-state probability $\rho$ is unknown to all.

Proposition 5 Suppose that the good state occurs in period 1. (a) All firms with a positive output earns positive profit. (b) An $\alpha$-firm earns more than a $\beta$-firm does.

Proof. (a) The profit of a firm in the good state, in which the market price is at $p_{1}^{g}$, is equal to

$$
\pi_{1}^{i g}=p_{1}^{g} q_{1}^{i}-\left(w \ell_{0}^{i}+F\right)(1+r),
$$

where $i=\alpha, \beta$. Since the expected profit of a firm is non-negative, and since the market price in the good state is higher than the expected price, the profit in (28) is positive if the output is positive. (b) It is clear that should a firm know that the market price is as high as $p_{1}^{g}$, it would want to produce more. Since an $\alpha$-firm has an output higher than that of a $\beta$-firm, and since the profit is strictly concave in labor input, an $\alpha$-firm must has a higher profit. Note that the profit of a $\beta$-firm may be zero.

By this proposition, $\pi_{1}^{\alpha g}>\pi_{1}^{\beta g}$. Graphically, the profit of an $\alpha$-firm in the good state, $\pi_{1}^{\alpha g}$, is depicted by point $\mathrm{K}$ in Figure 2 . These two realized profit levels are known to all the firms.

The firms then start to choose the optimal labor input for a new production to be completed in period 2. If each firm maintains the same good-state probability as before, and since the demand and technology conditions remain unchanged, it will choose the same labor input.

In this paper, we assume that the $\beta$-firms, after noticing that good state occurs in period 1, will revise upward their good-state probability. This is the herding effect we mentioned earlier. In the present context, two reasons can be introduced to explain the existence of herding. First, the $\beta$-firms note 
that their profits are less than those of the $\alpha$-firms. They may regret that they have not invested more. In particular, in the special case in which their perceived good-state probability is zero, they know that they have made a mistake. Even if their perceived good-state probability is positive, they may feel that they have underestimated the probability of the good state. It is then reasonable for them to revise their estimated good-state probability upward. The $\beta$-firm may feel even more strongly after a long series of good states, as these Asian countries experienced before the crisis.

Second, for many firms, the production decisions are made by managers or executives. Very often the performance of a manager is measured in terms of not just by how much profit he makes, but also by how the profit is compared with the profits made by similar firms. A manager hates to make a profit substantially less than what his firm's competitors are making. On the other hand, if everyone else is making a loss, making a loss will appear to be more acceptable. Because of this feature, managers tend to constantly revise their prediction so that they would not appear to be too far away from other managers' prediction. In the present model, the herding effect for the managers is assumed to be stronger in period 1 with the good state than in period 0 , because in period 1 with the good state the profits of the $\alpha$-firms are higher than those of the $\beta$-firms.

In this paper, the herding effect is captured by assuming that in period 1 the pessimistic $\beta$-firms replace their initial perceived good-state probability with that of the $\alpha$-firms, while the latter retain their initial perceived goodstate probability. As a result, all the firms have the same expectation of the good-state probability in period 2 , which is the same as $\rho_{1}^{\alpha}$. All firms now become identical, not just in technology but also in what they think about the probability of the good state in the next period. ${ }^{28}$ No superscript to identify the firms is needed in this and the next sections.

Based on the perceived good-state probability, all firms choose the optimal labor input in period 1, with the costs of labor and possibly other inputs covered by loans from banks or other financial intermediaries. The equilibrium of the market can be described by the following equations. First, the

${ }^{28}$ The assumption that full herding exists in this period is made for simplicity. A more realistic, but more complicated, model is to assume a multi-period model to analyze how gradual herding exists and to explain how pessimistic firms are getting more optimistic over time as the economy is growing. We believe that the simple model described here is good enough to bring out the points we want to make. 
output of each firm is:

$$
q_{2}=\phi\left(\widetilde{p}_{2} ; w, r\right)=f\left(g\left(\widetilde{p}_{2} ; w, r\right)\right),
$$

where the expected price $\widetilde{p}_{2}$ is defined by

$$
\widetilde{p}_{2} \equiv \rho_{2} h^{g}\left(D_{2}\right)+\left(1-\rho_{2}\right) h^{b}\left(D_{2}\right) .
$$

The total supply is given by

$$
Q_{2}=2 n \phi\left(\widetilde{p}_{2} ; w, r\right),
$$

which in equilibrium is equal to demand,

$$
Q_{2}=D_{2} \text {. }
$$

Equations (29) to (32) can be solved for the four unknowns: $q_{2}, \widetilde{p}_{2}, Q_{2}$, and $D_{2}$.

Alternatively, these four conditions can be combined together to yield the following reduced form:

$$
Q_{2}=2 n \phi\left[\rho_{2} h^{g}\left(Q_{2}\right)+\left(1-\rho_{2}\right) h^{b}\left(Q_{2}\right)\right],
$$

which can be solved for the aggregate output, $Q_{2}$.

Graphically, the equilibrium can be obtained from Figure 1. As explained, schedule EG describes the supply of housing by all the firms as a function of the market price (in the stationary state) or expected price, if all firms have the same expectation of the good-state probability. Based on the good-state probability perceived by all firms, the expected demand schedule $\tilde{h}$ can be constructed. The market equilibrium is the point of intersection, K, between the expected demand schedule and the aggregate supply schedule EG. The corresponding price levels $p_{2}^{g}$ and $p_{2}^{b}$ in the two states and the expected price $\tilde{p}_{2}$ are shown in the diagram. ${ }^{29}$ For comparison purpose, points $\mathrm{A}$ and $\mathrm{D}$ from Figure 4 , which show the equilibrium when the $\beta$-firms are not so optimistic, are also shown.

Proposition $6 Q_{1}<Q_{2}<2 Q_{1}$.

\footnotetext{
${ }^{29}$ This equilibrium can also be illustrated in Figure 3. By construction, schedule A* $\mathrm{B}^{*}$ is twice as high as schedule $\mathrm{AB}$, and thus represents function $2 n \sigma\left(Q_{1} ; \rho_{2}, w, r\right)$. The equilibrium output is represented by the interesecting points between schedule $\mathrm{A}^{*} \mathrm{~B}^{*}$ and a $45^{\circ}$-line from the origin.
} 
Proof. Refer to Figure 3. The equilibrium in period 1 is at point $\mathrm{F}$ if only $\alpha$-firms produces, or point $\mathrm{E}$ if all firms are producing, or somewhere between $\mathrm{E}$ and $\mathrm{F}$ if all $\alpha$-firms and some $\beta$-firms produce. In period 2 , when all firms are equally optimistic about the future so that all have the same output, the market equilibrium is at point $\mathrm{H}$. It is clear from the diagram that $Q_{2}>Q_{1}$ whether none, some, or all $\beta$-firms produce. To show the second inequality in the proposition, note that by construction, JF $=$ FG. Construct point I on the $45^{\circ}$-line so that GI is a horizontal line. Geometrically, GI $=\mathrm{GF}=\mathrm{FJ}$ $=\mathrm{OJ}$, and so $\mathrm{FI}=\mathrm{OF}$. This means that the output corresponding to point I will be twice the output $Q_{1}^{c}$. However, because schedule $\mathrm{A}^{*} \mathrm{~B}^{*}$ is strictly downward sloping, its intersection with the $45^{\circ}$-line, point $\mathrm{H}$, is lower than point $\mathrm{I}$. Since $\mathrm{H}$ is the equilibrium point in period 2 , the diagram shows that $2 Q_{1}^{c}>Q_{2}$. So the second inequality in the proposition holds in case (c) with only $\alpha$-firms producing. If some or all $\beta$-firms are producing, the period- 1 output is higher and the same inequality holds, too.

The first inequality in the above proposition is intuitive because of the increase in the production of the $\beta$-firms. The second inequality puts an upper bound on the increase in the output due to a rise in the optimism of the $\beta$-firms.

Proposition $7 p_{2}^{j}<p_{1}^{j}, j=g, b$.

Proof. This proposition follows from the first inequality in the previous proposition.

The previous two propositions suggest that the increase in the aggregate supply due to an increase in optimism of the type- $\beta$ firms has lowered the market price in either state. This will affect the profit of the $\alpha$-firms.

\section{The Bubbles}

This section examines how herding affects the profits of the firms in period 2. First of all, let us define a term to be used below: vulnerability of a firm. Recall that the condition of the market is unknown at the time a firm chooses its output based on the expected demand. Thus the realized profit of the firm depends on what state to occur in the next period. It is therefore possible that a firm may face a loss if the realized profit is negative when a bad state 
occurs. ${ }^{30}$ Such a possible loss makes the firm vulnerable, and in the present model its vulnerability is measured in terms of the loss when the bad state occurs in the next period. The vulnerability of a market is the total losses of all the firms when the bad state occurs.

\subsection{Vulnerability of the $\alpha$-firms}

We first focus on the profits of the $\alpha$-firms. Since the herding effect causes a rise in the aggregate supply and thus a drop in the price level in each state, the expected price level of all firms, $\widetilde{p}_{2}$, is less than $\widetilde{p}_{1}^{\alpha}$. This causes each $\alpha$-firm to have an output level less than that in period 1 . The new price level is shown in Figure 2, with the corresponding expected profit represented by point $\mathrm{A}$ on the profit schedule. As explained, the slope of the profit schedule at point A represents the output of an $\alpha$-firm. With this output level (and the corresponding labor input) chosen, the realized profit at any actual price level is given by line HGAJ, which has an equation given by:

$$
\pi_{2}=p_{2} q_{2}-\left(w \ell_{1}+F\right)(1+r),
$$

where $q_{2}$ and $\ell_{1}$ were chosen before period 2 . If the good (bad) state occurs so that the equilibrium price level is equal to $p_{2}^{g}\left(p_{2}^{b}\right)$, the realized profit of the firm is equal to

$$
\pi_{2}^{j}=p_{2}^{j} q_{2}-\left(w \ell_{1}+F\right)(1+r),
$$

where $j=g, b$. In Figure 2, if the good (bad) state occurs, the profit is depicted by point $\mathrm{J}(\mathrm{H})$. It is clear from the diagram that with the herding effect, the profit of an $\alpha$-firm in the good state is less than that without the herding effect. This result is intuitive because of a drop in the good-state price and the output level.

Since the purpose of this paper is to explain a financial crisis, let us say something more about the bad state. We first ask the question, does the herding effect make the firm (and also the market) more vulnerable? To answer this question, we can first compare the bad-state profits of an $\alpha$-firm in period 1 and period 2:

$$
\pi_{2}^{b}-\pi_{1}^{\alpha b}=\left(p_{2}^{b} q_{2}-p_{1}^{b} q_{1}^{\alpha}\right)-w\left(\ell_{1}-\ell_{0}^{\alpha}\right)(1+r) .
$$

\footnotetext{
${ }^{30}$ That does not mean that the firm is irrational. It is because the risk-neutral firm chooses its production based on expected profit.
} 
The difference between the two profits as given in (35) is represented by the vertical gap between points I and $\mathrm{H}$, or EF, in Figure 2. In general, the sign of this difference is ambiguous, meaning that the herding effect may increase or decrease the loss of an $\alpha$-firm in the bad state. To see this effect more clearly, define the following hypothetical profit for an $\alpha$-firm:

$$
\pi_{1}^{b \prime}=p_{1}^{b} q_{2}-\left(w \ell_{1}+F\right)(1+r),
$$

which is the profit of an $\alpha$-firm in a bad state in period 1 if it chooses the production plan in period $2,\left(\ell_{1}, q_{2}\right)$. In Figure $2, \pi_{1}^{b \prime}$ is represented by the vertical height of point G, or OD (loss). The profit effect of the herding effect as given in (35) can be rewritten as

$$
\pi_{2}^{b}-\pi_{1}^{\alpha b}=\left(\pi_{2}^{b}-\pi_{1}^{b \prime}\right)+\left(\pi_{1}^{b \prime}-\pi_{1}^{\alpha b}\right) .
$$

The term $\left(\pi_{2}^{b}-\pi_{1}^{b \prime}\right)$ is called the price effect, represented by DE in Figure 2 , while $\left(\pi_{1}^{b \prime}-\pi_{1}^{\alpha b}\right)$ can be called the output effect, represented by FD. The price effect is negative, i.e., an increase in the loss, because the herding effect causes a drop in the price level. The output effect is positive in this case, because the herding effect induces the firm to produce less, making the investment less risky. In the case shown in Figure 2, the output effect outweighs the price effect, meaning that the firm gets a smaller loss in the bad state because of the herding effect. ${ }^{31}$

\subsection{Vulnerability of the $\beta$-firms}

We now turn to the $\beta$-firms. If the production of $\beta$-firm in period 0 is zero, the herding effect definitely has increased the firm's vulnerability since its profit in the bad state in period 2 may be negative. We want to see whether its vulnerability is unambiguously higher with the herding effect even if it produces a positive output in period 0 . To do that, we need to determine the change in its profits,

$$
\pi_{2}^{b}-\pi_{1}^{\beta b}=\left(p_{2}^{b} q_{2}-p_{1}^{b} q_{1}^{\beta}\right)-w\left(\ell_{1}-\ell_{0}^{\beta}\right)(1+r) .
$$

As done before, the change in its profit as given by (38) can be disaggregated into the price effect and the output effect, i.e.,

$$
\pi_{2}^{b}-\pi_{1}^{\beta b}=\left(\pi_{2}^{b}-\pi_{1}^{b \prime}\right)+\left(\pi_{1}^{b \prime}-\pi_{1}^{\beta b}\right),
$$

\footnotetext{
${ }^{31}$ It is possible to show another case in which the price effect outweighs the output effect.
} 
where, as defined earlier, $\pi_{1}^{b \prime}$ is the hypothetical profit if a firm in the bad state in period 1 chooses the production decision $\left(\ell_{1}, q_{2}\right)$. We showed that the price effect is negative because of the drop in the bad-state price. The output effect for a $\beta$-firm is also negative, because the herding effect has caused the firm to produce more, while the firm would produce less should it be known in the previous period that the bad state is going to occur in period 1. We conclude that the herding effect, which is due to the increase in optimism of the $\beta$-firms, has increased their vulnerability in the next period.

\subsection{Vulnerability of the market}

We showed that the herding effect may hurt or improve the vulnerability of the $\alpha$-firms, but will definitely hurt that of the $\beta$-firms. We now want to show how it may affect the vulnerability of the market as a whole. ${ }^{32}$

The change in the profit of all the firms in the bad state in period 2 is

$$
\begin{aligned}
& 2 n \pi_{2}^{b}-n\left(\pi_{1}^{\alpha b}+\pi_{1}^{\beta b}\right) \\
= & n\left(2 p_{2}^{b} q_{2}-p_{1}^{b} q_{1}^{\alpha}-p_{1}^{b} q_{1}^{\beta}\right)-w n\left(2 \ell_{1}-\ell_{0}^{\alpha}-\ell_{0}^{\beta}\right)(1+r) .
\end{aligned}
$$

As we did before, this change in profit can be disaggregated into the price effect and the output effect, i.e.,

$$
2 n \pi_{2}^{b}-n\left(\pi_{1}^{\alpha b}+\pi_{1}^{\beta b}\right)=2 n\left(\pi_{2}^{b}-\pi_{1}^{b \prime}\right)+n\left(\pi_{1}^{b \prime}-\pi_{1}^{\alpha b}\right)+n\left(\pi_{1}^{b \prime}-\pi_{1}^{\beta b}\right) .
$$

The previous analysis shows that the price effect is negative for both types of firms. The sum of the output effects for one $\alpha$-firm and one $\beta$-firm is

$$
\begin{aligned}
& \left(\pi_{1}^{b \prime}-\pi_{1}^{\alpha b}\right)+\left(\pi_{1}^{b \prime}-\pi_{1}^{\beta b}\right) \\
= & p_{1}^{b}\left(2 q_{2}-q_{1}^{\alpha}-q_{1}^{\beta}\right)-w\left(2 \ell_{1}-\ell_{0}^{\alpha}-\ell_{0}^{\beta}\right)(1+r) .
\end{aligned}
$$

Proposition 6 shows that the aggregate output in period 2 is greater than that in period 1, i.e., $2 q_{2}>q_{1}^{\alpha}+q_{1}^{\beta}$. Since there are losses in the bad state, Proposition 6 suggests that the market has over-invested in period 2. Consider the

\footnotetext{
${ }^{32}$ Of course, if the herding effect hurts the vulnerability of the $\alpha$-firms as well, it will hurt the whole market. We want to see whether the whole market is hurt even if the $\alpha$-firms are not.
} 
following ranking:

$$
\begin{aligned}
& p_{1}^{b}\left(q_{1}^{\alpha}+q_{1}^{\beta}\right)-\left(w \ell_{0}^{\prime}+F\right)(1+r) \\
\geq & p_{1}^{b}\left(q_{1}^{\alpha}+q_{1}^{\beta}\right)-\left[w\left(\ell_{0}^{\alpha}+\ell_{0}^{\beta}\right)+F\right](1+r) \\
> & 2\left[p_{1}^{b} q_{2}-\left(w \ell_{1}+F\right)(1+r)\right],
\end{aligned}
$$

where $\ell_{0}^{\prime}$ is the optimal labor input for the two firms to produce $q_{1}^{\alpha}+q_{1}^{\beta}$ in period 0 (production completed in period 1), if they can coordinate their production. The first inequality in (41) is due to the fact that their chosen inputs $\ell_{0}^{\alpha}+\ell_{0}^{\beta}$ may not be efficient; the second inequality is due to overinvestment in period 1 (production completed in period 2). The second inequality in (41) implies that the output effect for the market as given by (40) is negative. We now summarize the above results by the following proposition:

Proposition 8 Suppose that in period 1 all $\beta$-firms become as optimistic as the $\alpha$-firms. (a) All $\alpha$-firms may or may not become more vulnerable in the sense that their loss in the bad state may or may not be higher than before. (b) All $\beta$-firms are more vulnerable. (c) The market as a whole is more vulnerable.

The increase in the vulnerability of the market shows the damage of the herding effect to the market and economy. However, the effect hurts not just the market, but also possibly the economy. We now introduce the following concepts of bubbles. Specifically, in this paper we say that bubbles are formed

(1) when the firms are overoptimistic about the occurrence of good states or overstate the conditions of good states; or

(2) when the total losses of the firms in the bad state are so huge that there is a widespread bankruptcy, creating bad loans to the banks, and when the economy as a whole has difficulty in repaying the loans borrowed from abroad; or

(3) when the total losses of a sufficient percentage of the firms in the market are so big that other parts of the economy are adversely affected, causing significant deterioration in the confidence in the economy, capital flight, and speculative attacks on the currency. 
Criterion (1) refers to the case in which the firms (or other agents) put too much weight on the possible occurrence of good states. In the present model, bubbles are said to occur when the firms believe that the good-state probability is greater than the actual probability, $\rho_{2}>\rho$. The difficulty of applying this criterion to identify bubbles is that the actual probability, $\rho$, is not observable.

There may exist special cases in which the market becomes so overheated that many people easily conclude that widespread overoptimism occurs. To these people, bubbles exist in the market. However, that does not mean that people who invested under these conditions are irrational. In fact, it is quite possible that more people, including rational ones, could keep on investing despite the fact that the market has been over-heated. Some reasons can be offered to explain this phenomenon. First, many emerging economies took off not too long ago before the crisis, and then experienced impressive but nearly uninterrupted growth. This could easily make people get over-optimistic. Second, people originally pessimistic could be influenced by the successes of people who are more optimistic and aggressive in the past. They could very well follow the crowd and become more optimistic and aggressive. In other words, those aggressive and successful taught those pessimistic people to be aggressive. Third, the system also works to encourage managers of firms to be more aggressive in growing markets. They are afraid of making profits significantly lower than those made by similar firms, while they fear less about losses if similar firms are making similar losses. The last two points are just the herding effect introduced above. Fourth, even if people know that bubbles have been formed in the sense that the market is over-heated, they could still want to invest, because they hope that they can get a profit before the bubbles burst. In this case, people know that there are bubbles, but they just do not know when they will burst.

Criteria (1) is close to how bubbles are defined in the literature. For example, Flood and Hodrick (1990: 88) wrote, "A bubble thus represents a deviation of the current market price of the asset from the value implied by market fundamentals." In the present model, we say that a bubble is formed when the subjective good-state probability is too high or when the conditions of the future are overstated. However, the difficulty in forecasting a bubble in the future based on the present definition and the Flood-Hodrick concept is that they are based on some unobservable variables.

Criteria (2) and (3) are based more on observable variables during bad states. For example, if the supply and demand in a bad state are know, it is 
possible to determine the loss a firm may receive if the bad state occurs, and to determine the losses of all relevant firms. Bubbles are formed when these losses are bigger than this market or the economy can absorb. In particular, these losses can create negative externality to other parts of the economy. One may say that for the economy it may be bearable if only a few firms go bankrupt, but is unbearable if widespread bankruptcy occurs.

These two criteria are based on the existence of externality in the housing market, especially when widespread failure of firms arises. However, the criteria lead to different consequences. While criterion (2) emphasizes the inability to repay foreign loans, criterion (3) focuses on currency speculation, capital flight, and currency crisis.

Note that these two criteria do not require the knowledge of the unobservable probabilities of states. ${ }^{33}$

\section{The Crash}

In the previous section, we explained the formation of bubbles using a simple model. In this section, we try to extend it in two directions: the existence of more periods and an improvement in the conditions of the good state. These extensions will give more insights into the crisis.

\subsection{Multiperiods}

What happens to the market and the economy when there are more than two periods? The answer, as the above analysis shows, depends on what happens in period 2. If the bad state occurs, then the firms get losses. If the good state occurs, they receive profits. ${ }^{34}$

The interesting case is the one in which both periods 1 and 2 are marked by good states. These successes can boost the general level of optimism in the market. First, the originally optimistic firms may be more aggressive. Second, the originally not so optimistic firms may, due to the herding effect explained above, become more optimistic. As shown earlier, the rise in the general level of optimism will encourage the firms to produce more, thus

\footnotetext{
${ }^{33}$ Criteria (2) and (3) do suggest that bubbles were formed in the Thai housing markets prior to the crisis.

${ }^{34} \mathrm{~A}$ more complete analysis requires a multi-period model, but it is beyond the scope of this paper. For the present purpose, only a qualitative analysis is provided here.
} 
lowering the price level in a bad state. As a result, the investment becomes riskier because the losses in the bad state will be greater.

Many emerging markets are characterized by successive periods of good states. We explained that these good states can make people overoptimistic and too aggressive. As the number of periods of good states extends, the vulnerability of the firms and the market increases. The losses of the firms could be bigger the later a bad state occurs.

\subsection{Better Good States}

In the previous sections, it is assumed that the conditions of both states in period 2 remain the same as in period 1. This assumption is limited because it has not taken into account the fact that these emerging economies are growing. It is now relaxed. To capture the feature that the economy is growing, we assume that the good state becomes better in period 2 while the bad state remains unchanged. However, the probability of the good state is unchanged, and is also unknown to everyone.

We now write the inverse demand function in a good state as $p^{g}=$ $h^{g}\left(D_{2}, \gamma\right)$, where

$$
h_{D}^{g} \equiv \frac{\partial h^{g}}{\partial D_{2}}<0 ; \quad h_{\gamma}^{g} \equiv \frac{\partial h^{g}}{\partial \gamma}>0,
$$

and where the value of $\gamma$ in period 1 is $\gamma_{0}$. The equilibrium condition (33) reduces to

$$
Q_{2}=2 n \phi\left[\rho_{2} h^{g}\left(Q_{2}, \gamma\right)+\left(1-\rho_{2}\right) h^{b}\left(Q_{2}\right)\right] .
$$

Treating $\gamma$ as a parameter, equation (42) is totally differentiated to give

$$
\frac{\mathrm{d} Q_{2}}{\mathrm{~d} \gamma}=\frac{2 n f^{\prime} g^{\prime} \rho h_{\gamma}^{g}}{1-2 n f^{\prime} g^{\prime}\left[\rho h_{Q}^{g}+(1-\rho) h^{b \prime}\right]}>0 .
$$

The sign of the derivative in (43) is not surprising, as an increase in demand (in at least one of the states) would encourage more production. The effect of an improvement in the demand on the profit of a firm in a bad state is equal to

$$
\frac{\mathrm{d} \pi_{2}^{b}}{\mathrm{~d} \gamma}=\frac{\partial p^{b}}{\partial Q_{2}} \frac{\mathrm{d} Q_{2}}{\mathrm{~d} \gamma} q_{2}<0
$$

where the first-order condition (the envelope theorem) has been used. What condition (44) shows is that an improved good state in period 2 will encourage 
firm to invest more, but will make the investment riskier at the same time. These results are summarized in the following proposition:

Proposition 9 A increase in the demand for housing in a good state induces the firms to produce more housing and makes such investment riskier.

\section{Concluding Remarks}

This paper introduces a simple model to explain the formation of bubbles in the housing market in an emerging economy like Thailand, which was the first one that was forced to give up its currency pegging policy after months of attack from speculators and huge capital flight.

Housing is a durable good, and its production requires sufficient time and capital. For an economy in which investors have access to the international capital market, quite possibly rapid housing production leads to external debts. Therefore development of a domestic housing market is associated with risks about the future demand and the risks that failed firms could not repay external loans, thus damaging the creditworthiness of the economy in international capital markets.

Of course, if the economy remains on the good side all the time so that all the housing units produced can be sold at profitable prices, firms have no trouble in repaying external debts. Risks exist because bad times can happen and because bubbles can be formed.

In this paper, different concepts of bubbles are introduced. When the investors are overoptimistic, they oversupply. Such oversupply will lead to drop in prices in all possible states, thus raising the vulnerability of the firms during bad times. Even if it is not obvious that firms are overoptimistic, bubbles exist if there is a danger that a large number of firms may experience huge losses. When these firms fail, they create bad loans to financial institutions, which may have difficulties in repaying the loans they raise abroad.

Two fundamental questions arise. Why would firms become overoptimistic? Why would firms be willing to invest in the housing market, and why would financial institutions be willing to lend them money for investment, if it is recognized that there are bad times when many of the firms may not be able to repay their loans?

The answers we provide to the first question is that overoptimism could exist when: (i) housing production takes time while the future is uncertain; 
(ii) the probability of a particular state is unobservable; (iii) the history of growth of the emerging economy is short, making reliable estimation of the probabilities of states difficult; (iv) people tend to act close to each other, a phenomenon called the herding effect, and (v) long periods of good times would cause people to be over-confident about the probability of good times in the future.

The answer to the second question can be found from the following facts/conditions: (a) bankruptcy does not represent all the costs of failed investment for the investors; (b) moral hazard exists in the domestic financial institutions, which believe that the government will bail them out when they are in trouble; (c) moral hazard exists in the international financial institutions, which lend money to the domestic financial institutions, believing that some international organizations such as the International Monetary Fund will bail out the country if troubles arise.

The present paper also points out an irony in these emerging market. The vulnerability of the firms and the market can be enhanced by the growth of the economy in two ways: (a) if the economy experiences more periods of good time; or (b) if the demand for housing in a particular state improves. In each of these cases, firms are induced to invest more, making their investment riskier. 


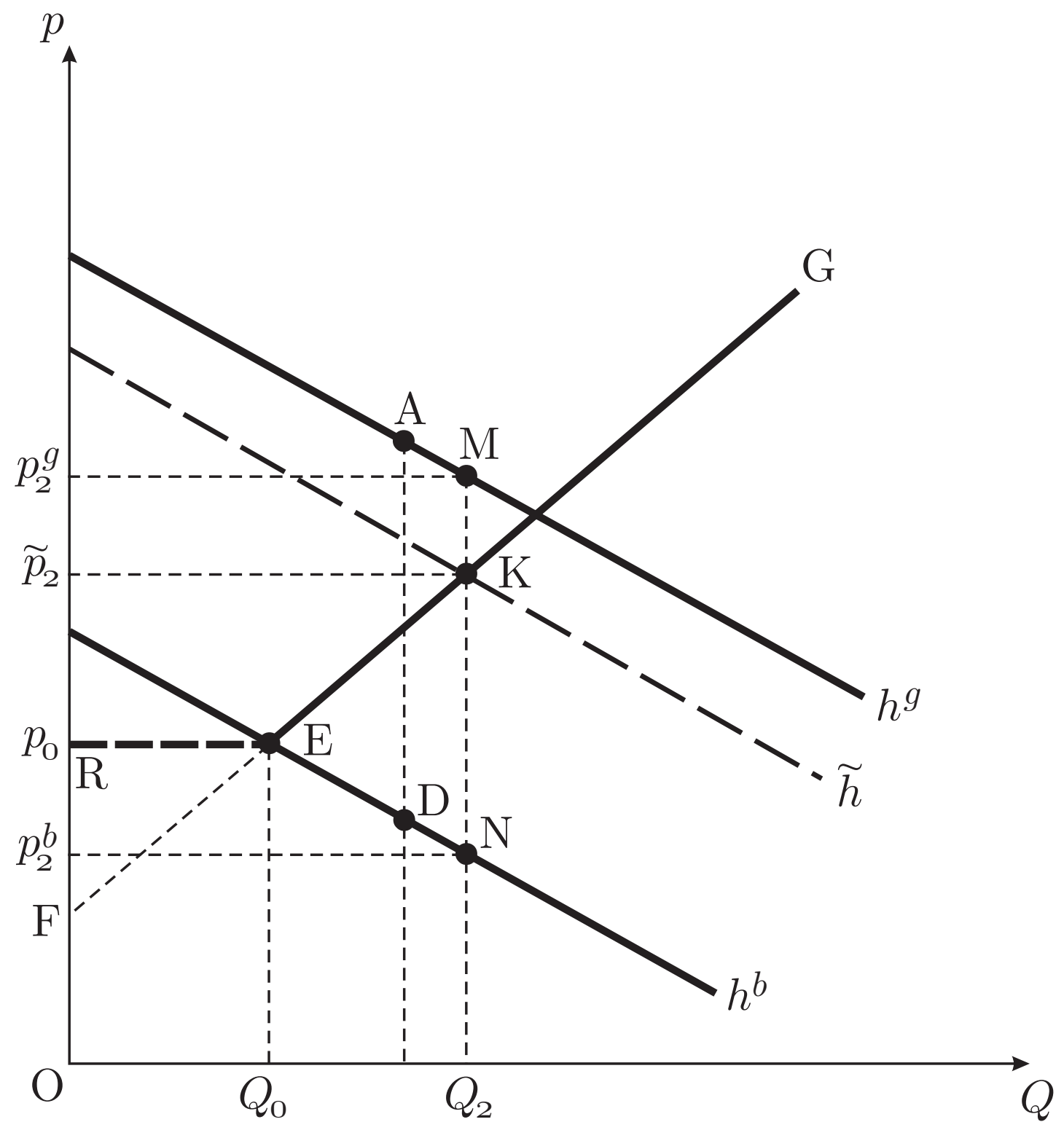

Figure 1

Market Equilibria in Periods 0 and 2 


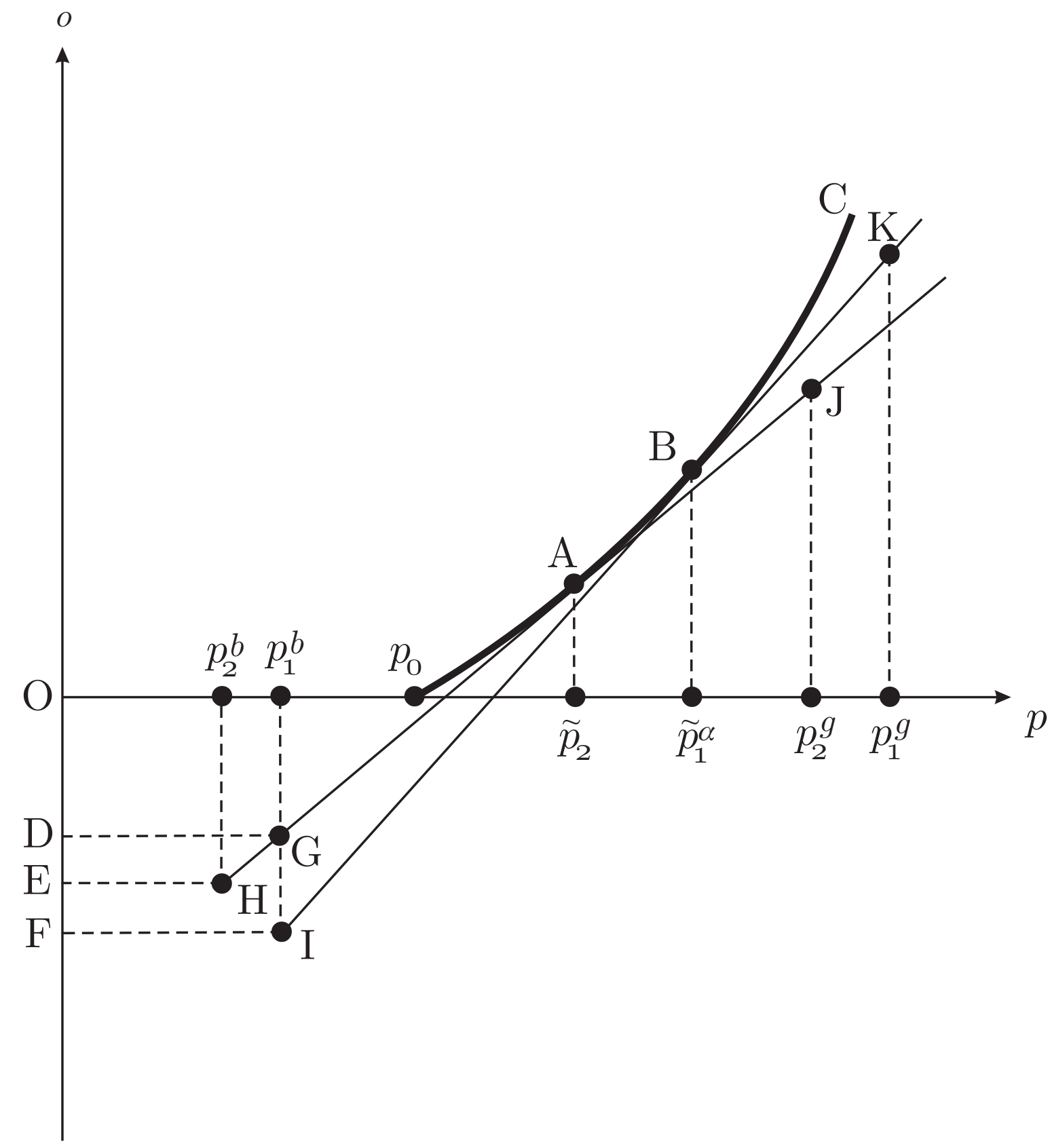

Figure 2

The Profit Function 


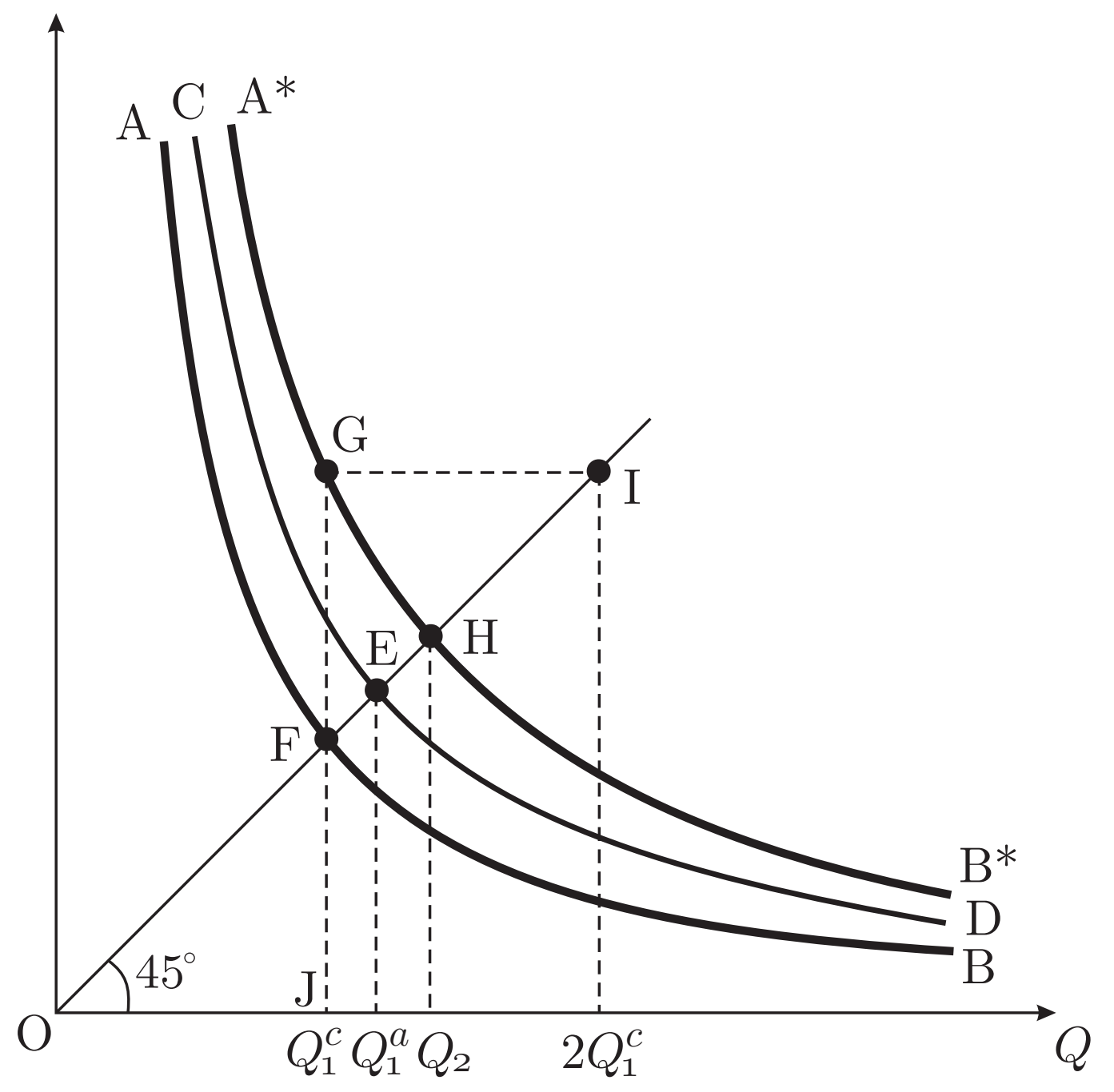

Figure 3

Various Possible Equilibrium Outputs 


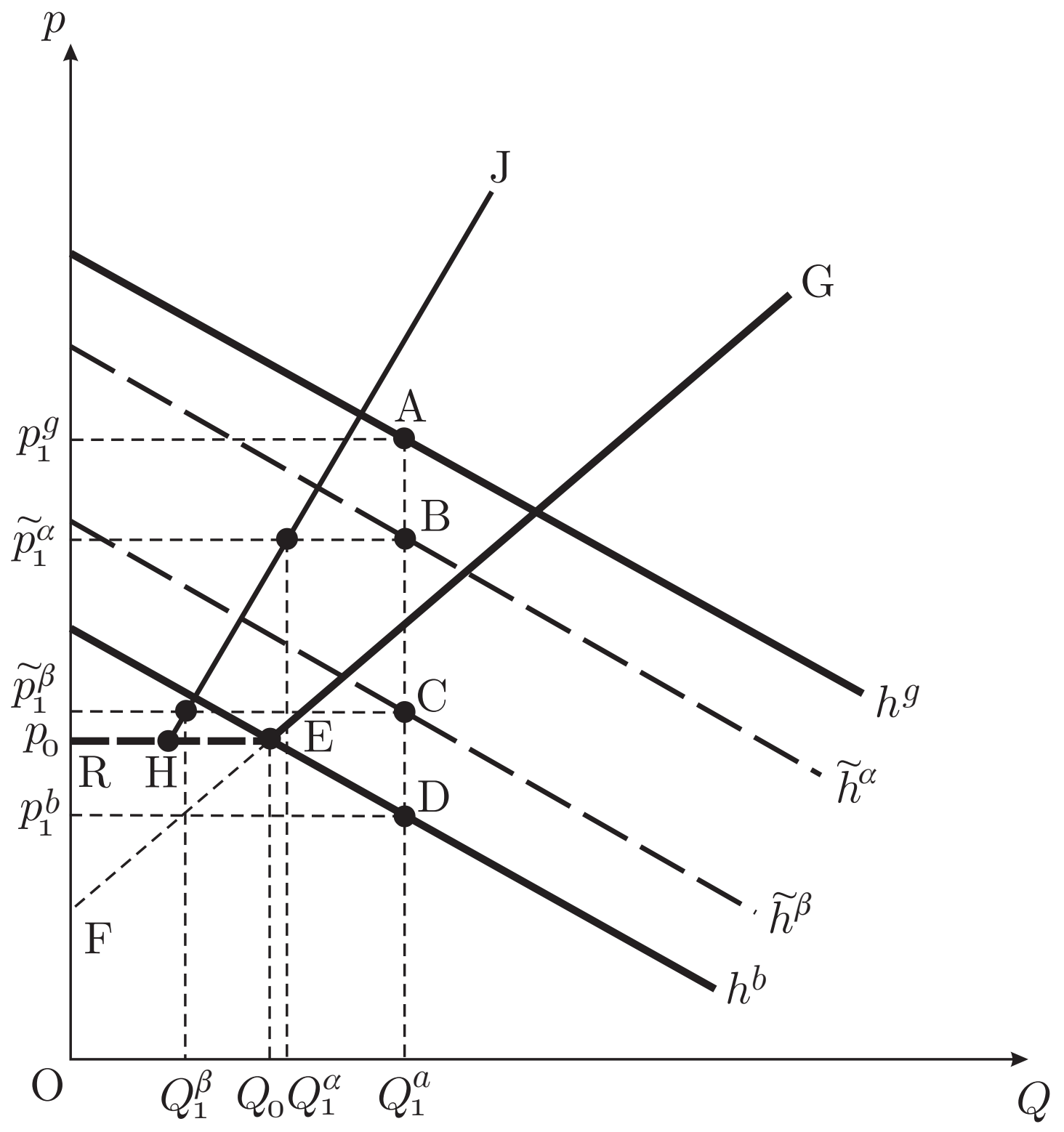

Figure 4

Market Equilibrium with All Firms Producing 


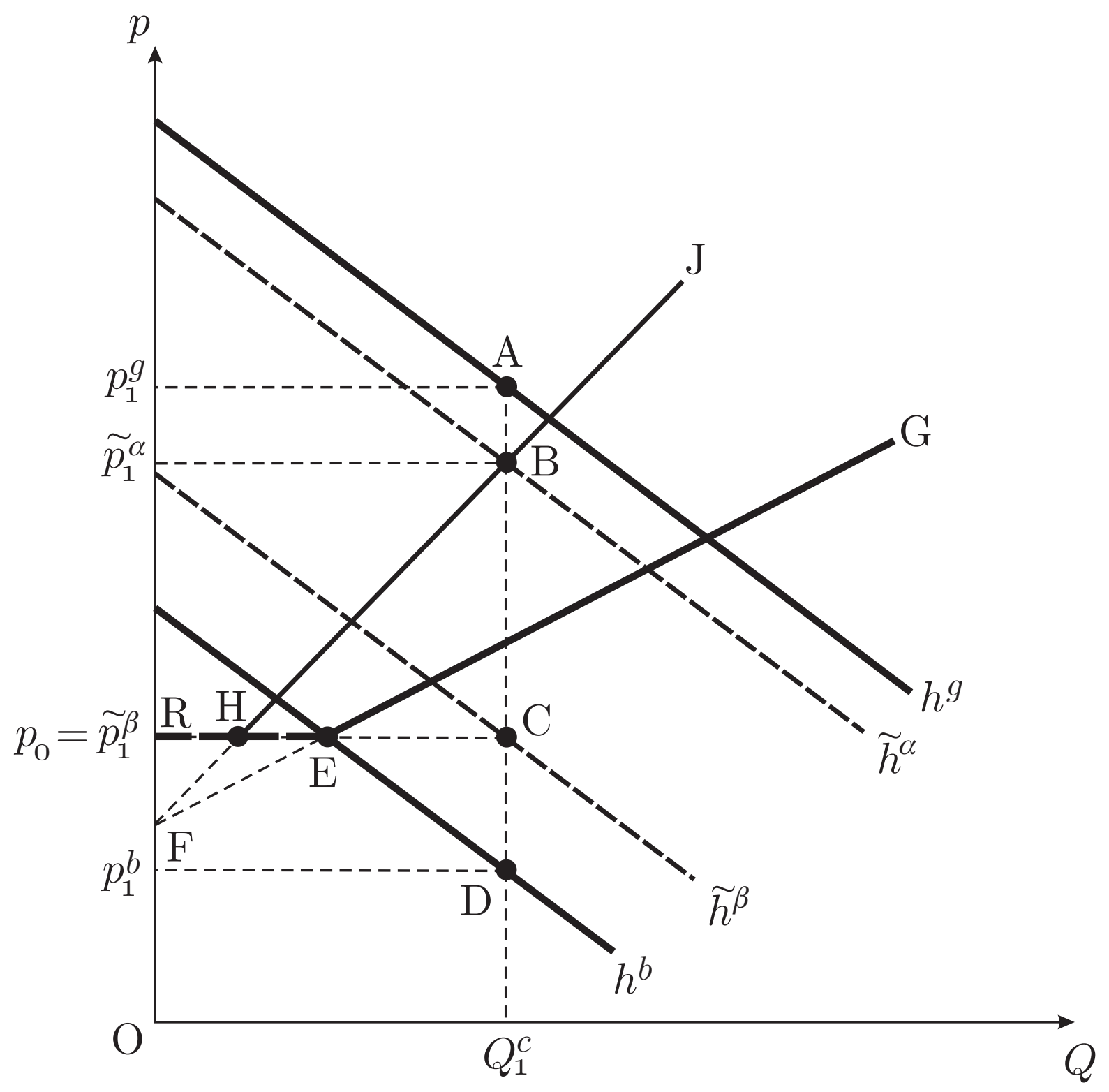

Figure 5

Market Equilibrium with $\alpha$-Firms Producing 


\section{References}

[1] Calvo, Guillermo and Enrique Mendoza, 1998. "Rational Herd Behavior and the Globalization of Securities Markets," Unpublished Manuscript, University of Maryland.

[2] Corsetti, Giancarlo, Paolo Pesenti, and Nouriel Roubini, 1998. "What Caused the Asian Currency and Financial Crisis, Parts I and II," Mimeo., available at http://www.stern.nyu.edu/ nroubini/ asia/AsiaHomepage.html.

[3] Devenow, Andrea and Ivo Welch, 1996. "Rational Herding in Financial Economies," European Economic Review, 40: 603-615.

[4] Krugman, Paul, 1998, "Currency Crises," Mimeo., MIT.

[5] Lo, Ming Chien, and Kar-yiu Wong, 1998. "Troubled Countries in the Asian Crisis: Some Statistical Data," available at http://faculty.washington.edu/karyiu/

[6] Parnsoonthorn, Krissana, 1996. "Year-End '96 Economic Review," Bangkok Post, December. This article is available online at http://www.bkkpost.samart.co.th/news/BParchive/y_end_eco_rev_new/ yr96prop.html.

[7] Renaud, Bertrand, Ming Zhang, and Stefan Koeberk, 1998. "How the Thai Real Estate Boom Undid Financial Institutions: What Can Be Done?" Mimeo., World Bank.

[8] Saxena, Sweta C. and Kar-yiu Wong, 2000. "The Economics of Currency Crisis and Capital Control: A Survey," Mimeo., University of Washington.

[9] Scharfstein, David S. and Jeremy C. Stein, 1990. "Herd Behavior and Investment," American Economic Review, 80, No. 3: 465-479.

[10] Terdudomtham, Thammavit, 1997. "The Bubble Finally Burst," Bangkok Post, December. This article is available online at http://www.bkkpost.samart.co.th/news/BParchive/ecoreview97/ review9701.html. 
[11] Wong, Kar-yiu, 1995, International Trade in Goods and Factor Mobility, Cambridge, Mass.: MIT Press.

[12] Wong, Kar-yiu (ed.), 1998. The Asian Crisis: What Has Happened?, A manuscript on the Asian crisis. The manuscript can be downloaded at http://faculty.washington.edu/karyiu/.

[13] Wong, Kar-yiu, 2000. "Firm Failure and Financial Crisis: The Experience of South Korea," Journal of the Korean Economy, 1 (1): 23-51. 